\title{
Mortality predictors of epilepsy and epileptic seizures among hospitalized elderly
}

Preditores de mortalidade de epilepsia e crises epilépticas entre idosos hospitalizados

Telma M. R. de Assis' ${ }^{1}$ Aroldo Bacellar', Gersonita Costaํ', Osvaldo J. M. Nascimento²

\begin{abstract}
Epilepsy and epileptic seizures are common brain disorders in the elderly and are associated with increased mortality that may be ascribed to the underlying disease or epilepsy-related causes. Objective: To describe mortality predictors of epilepsy and epileptic seizures in elderly inpatients. Method: Retrospective analysis was performed on hospitalized elderly who had epilepsy or epileptic seizures, from January 2009 to December 2010. One hundred and twenty patients were enrolled. Results: The most common etiology was ischemic stroke (37\%), followed by neoplasias (13\%), hemorrhagic stroke (12\%), dementias (11.4\%) and metabolic disturbances (5.5\%). In a univariate analysis, disease duration ( $p=0.04)$, status epilepticus $(p<0.001)$ and metabolic etiology $(p=0.005)$ were associated with mortality. However after adjustment by logistic regression, only status epilepticus remained an independent predictor of death (odds ratio $=13 ; 95 \% \mathrm{Cl}=2.3$ to 72 ; $p=0.004)$. Conclusion: In this study status epilepticus was an independent risk factor for death during hospitalization.
\end{abstract}

Keywords: elderly, epilepsy, epileptic seizures, mortality, status epilepticus.

\section{RESUMO}

Epilepsia e crises epilépticas são transtornos cerebrais comuns em idosos e estão associadas com uma taxa de mortalidade elevada que pode ser atribuída à etiologia ou a causas relacionadas à epilepsia. Objetivo: Descrever preditores de mortalidade em pacientes idosos internados com epilepsia e crise epiléptica. Método: Estudo retrospectivo, envolvendo idosos hospitalizados, de 60 anos ou mais, que foram admitidos de janeiro de 2009 a dezembro de 2010 por terem apresentado epilepsia e crises epilépticas durante a hospitalização. Cento e vinte pacientes foram incluídos no estudo. Resultados: A etiologia mais comum foi o acidente vascular cerebral isquêmico (37\%), seguido por neoplasias (13\%), acidente vascular cerebral hemorrágico (12\%), demências (11,4\%) e distúrbios metabólicos (5,5\%). Na análise univariada, duração da doença $(p=0,04)$, estado de mal epiléptico $(p<0,001)$ e etiologia metabólica $(p=0,005)$ estiveram associados com mortalidade. Entretanto, após ajuste por regressão logística, apenas estado de mal epiléptico permaneceu como preditor independente de morte (odds ratio = 13; IC95\% = 2,3 a 72; p = 0,004). Conclusão: Neste estudo, estado de mal epiléptico foi um fator independente de risco para morte durante hospitalização.

Palavras-chave: crise epiléptica, epilepsia, idosos, mortalidade, estado de mal epiléptico.

People with epilepsy and epileptic seizures are at an increased risk of dying when compared to the general population mostly in special groups such as those with acute symptomatic seizures or status epilepticus (SE). Patients over 75 years have higher incidence of acute symptomatic seizures, epilepsy and SE compared to other age groups ${ }^{1}$. Acute symptomatic seizures represent $40 \%$ of all seizures and $50 \%-70 \%$ of SE and are more commonly seen at extreme ages, with the highest incidence rates seen in children below 1 year of age and adults 60 years and above ${ }^{2,3}$.
Notwithstanding its high incidence, epilepsy in old-aged people often goes unrecognized and neglected. In contrast, the prevalence is relatively low possibly because of the increased mortality rates for old-aged people due to its etiology $^{4}$. Studies reported that neurological disorders such as cerebrovascular disease and neoplasias, contribute to excess mortality in patients with epilepsy. Studies on mortality in epilepsy have been reported from a few developed countries. In high-income countries, the mortality rate in elders with epilepsy is two to three times higher than in the general population, and the highest excess mortality is

${ }^{1}$ Hospital São Rafael, Departamento de Neurologia, Salvador BA, Brazil;

${ }^{2}$ Universidade Federal Fluminense, Departamento de Neurologia, Rio de Janeiro RJ, Brazil.

Correspondence: Telma M. Rocha de Assis; Av São Rafael, 2152; 41253-190 Salvador BA, Brasil; E-mail: telmasaj@gmail.com

Conflict of interest: There is no conflict of interest to declare.

Received 16 December 2014; Received in final form 18 February 2015; Accepted 10 March 2015. 
found above 75 years $^{6}$. In SE the mortality rate may reach to $50 \%$ especially as it related to stroke, systemic metabolic disorders and other comorbidities ${ }^{7}$.

Risk factors for epilepsy and seizures etiology vary with age. Stroke is the most important underlying etiology of new-onset epilepsy in people 65 years old and older reaching 30 to $50 \%$ of identified causes ${ }^{8,9,10}$. Cerebrovascular disease is probably the underlying cause of a proportion of seizures of unknown etiology, because older people with epilepsy have several vascular risk factors even for ones that have not had a previous stroke.

Acute symptomatic seizures often occur in the elderly in the onset of illnesses such as stroke, traumatic brain injury or in the course of toxic or metabolic disorders ${ }^{11}$. Drugs known for their potential effect in lower the seizure threshold such as opioids pain killers, antibiotics, tricyclic antidepressants, $\beta$-blockers and some antipsychotics agents (phenothiazine, olanzapine, clozapine), are commonly prescribed for elderly patients and should be avoided $\mathrm{d}^{12,13,14,15}$.

SE is a medical and neurological emergency that is associated with significant morbidity and mortality. It is a condition with relevant severity in older individuals not only by the expressive increase in the incidence compared to the general population, but also because of comorbidities and peculiarities of treatment that may result in worse prognosis. In elderly patients SE is a common life-threatening condition because $30 \%$ of acute symptomatic seizures arise as SE compared with $2 \%-16 \%$ of epileptic patients ${ }^{9,14}$. SE presentation may be very subtle in this age-group, especially when it follows an acute injury of the central nervous system, such as stroke, anoxia, metabolic and alcohol-related insults, and low anticonvulsant drug concentrations ${ }^{16}$.

Mortality studies in epilepsy in resource-poor countries are scarce and difficult to conduct because death certificates are not reliable, autopsies are not easily obtained and cause of death is often poorly described ${ }^{17}$.

Epileptic seizure in the elderly is associated with a sharp increase in mortality during the first year following the onset of seizures, so it is important for physicians treating these patients to be aware of epilepsy-related characteristics that are associated with worse outcome ${ }^{6}$. This study aims to identify predictors of mortality in elderly inpatients admitted to a tertiary general hospital in Salvador, Brazil

\section{METHOD}

Retrospective, cross-sectional study was performed on elderly patients, defined in this study as those 60 years old and older, consecutively admitted due to several reasons, in a tertiary center from January $1^{\text {st }}, 2009$ through December $31^{\text {nd }}$, 2010. We analyzed medical records of 782 patients and selected 120 patients whose onset of epilepsy or epileptic seizure was at their sixties and above. All patients were under assistance of the neurology team. We excluded patients in whom it was not possible to set the time of the onset of epilepsy or epileptic seizure and those who had epileptic seizures previous at the cutting age (60 years old). We also conducted a telephone interview with patient or caregiver for further information, when necessary.

The diagnosis of epilepsyand epileptic seizures was established according to the concepts of Glossary of Descriptive Terminology for Ictal Semiology: Report of the International League Against Epilepsy Task Force on Classification and Terminology ${ }^{18}$. We used the recommendation for a definition of acute symptomatic seizure endorsed by ILAE Executive Committee ${ }^{19}$.

We analyzed the etiologies of epilepsy and epileptic seizures, case fatality rate, comorbidities such as systemic arterial hypertension, diabetes mellitus, dyslipidemia, age and gender.

The study was approved by the Research Ethics Committee of the Hospital São Rafael, Salvador, Bahia, Brazil.

The statistical analysis was performed with SPSS, version 14.0. The etiological prevalence was described as proportion. The mortality incidence was described as percentages and evaluated by Confidence Interval (CI) at 95\%. To identify predictors of death, the subgroup of hospital death was compared with subgroup that survived. The categorical variables were compared by the Chi-square and quantitative variables by $\mathrm{t}$-Student and non parametric Mann-Whitney test. Categorical variables with the difference between the two groups with $\mathrm{p}<0.10$ were adjusted by logistic regression to identify independent predictors of hospital death.

\section{RESULTS}

One hundred and twenty patients were enrolled in the study, aged $75 \pm 9.1$ years (mean \pm SD), $55 \%$ (66) females. The analysis of cardiovascular risk factors unveiled systemic arterial hypertension as the more prevalent condition in $88 \%$ (106) patients. Diabetes mellitus was present in 32\% (38) and dyslipidemia in $26 \%$ (31) of patients. The disease duration was $1.1 \pm 2.2$ years (Table 1 ).

Acute symptomatic seizures were found in $7.5 \%$ (9) patients in close relation with antibiotic use (5 patients), alcoholism in patient with cerebrovascular disease and concomitant renal failure ( 1 patient), metabolic disorder (2 patients) and in the set of acute ischemic stroke (1 patient). SE occurred in $7.5 \%$ (9) patients and we found etiological association with previous traumatic brain injury (1 patient), sepsis (2 patients), anoxic encephalopathy (1 patient), metabolic disorder (2 patients), ischemic stroke (2 patients), neoplasia (1 patient).

The type of epileptic seizure was ascertained in $61.8 \%$ (75) of patients. Generalized seizures were described in $37.2 \%$ (45) of patients and focal seizures in $24.6 \%$ (30) of them (Table 1).

Ischemic stroke was the most common etiology (37\%), followed by hemorrhagic stroke $(12 \%)$, intracranial neoplasias (13\%), Alzheimer dementia (6.7\%), others dementias (4.7\%), metabolic disturbance (5.5), others etiologies (brain 
injury sequel, normal pressure hydrocephalus, meningitis, hemangioma, anoxic encephalopathy, alcoholism, antibiotics), and unknown (21.1\%) (Figure 1).

The univariate analysis of factors related to hospital death showed a mortality rate of $26 \%$ (95\% IC; $18 \%$ to $34 \%$ ). Of this group, $61 \%$ were female $(n=19)$ and mean age $76 \pm 11$, with no statistically significant difference among the groups ( $p=0.41$ and $p=0.81$, respectively). Patients with shorter disease duration $(0.39 \pm 0.80$ years $)$ had a higher mortality rate $(p<0.04)$. The comorbidities such as systemic arterial hypertension, diabetes mellitus, dyslipidemia were associated with mortality in $87 \%$ ( $p=0.83), 39 \%(p=0.33)$, and $30 \%(p=0.61)$, respectively. The etiologies of epilepsy and epileptic seizures associated with death were: ischemic stroke, 36\% ( $p=0.87)$, intracranial neoplasias, $16 \%(\mathrm{p}=0.60)$, metabolic disturbances,

Table 1. Clinical characteristics of the sample.

\begin{tabular}{lc}
\hline Variable & \\
\hline Sample size & 120 \\
Demographic data & $75 \pm 9.1$ \\
Age (years) & $66(55 \%)$ \\
Gender female & $18(15 \%)$ \\
Marital status (unmaried) & $19(16 \%)$ \\
Assistance by SuS & \\
Cardiovascular risk factors & $38(32 \%)$ \\
Diabetes & $106(88 \%)$ \\
Systemic arterial hypertension & $31(26 \%)$ \\
Dyslipidemia & \\
Clinical data of epilepsy & $1.1 \pm 2.2$ \\
Disease duration (years) & $9(7.5 \%)$ \\
Status epilepticus & $9(7.5 \%)$ \\
Acute symptomatic seizure & \\
Epileptic seizure type & $40(33 \%)$ \\
Generalized & $7(5.8 \%)$ \\
Secondarily generalized & $16(13 \%)$ \\
Simple partial & $7(5.8 \%)$ \\
Complex partial & $5(4.2 \%)$ \\
Myoclonic & $45(38 \%)$ \\
Not classified &
\end{tabular}

SUS: Sistema Único de Saúde.
$16 \%(p=0.005)$, hemorrhagic stroke 6.5\% ( $p=0.29)$, Alzheimer dementia $3.2 \%(p=0.37)$ and other dementias $6.5 \%(p=0.67)$ (Table 2). In the group of patients who died, $23 \%$ had status epilepticus ( $\mathrm{p}<0.001$ ). Only status epilepticus, metabolic disorders and disease duration were associated with death. The analysis etiology of the epileptic seizure shows similar mortality rates for different etiologies, however, metabolic disturbances contributes with $71 \%$ of mortality $(n=7)$. When compared simultaneously, there was no statistically significant difference among all groups ( $\mathrm{p}=0.14$ ) (Figure 2).

When the variables associated with hospital mortality, status epilepticus, metabolic disorders and disease duration, were submitted to logistic regression analysis only SE was independent predictor of death $(\mathrm{OR}=12.8$; $95 \% \mathrm{CI}=2.3$ to 72.2 ; $\mathrm{p}=0.004)$. Metabolic disorders and disease duration had no longer statistical significance after adjustment to SE (Table 3).

The findings, both in univariate and multivariate analysis, demonstrated that $78 \%$ of patients with SE died, compared to $22 \%$ of patients who didn't have SE $(\mathrm{RR}=3.6: 95 \% \mathrm{CI}=2.4$ to $5.9 ; \mathrm{p}=0.004)$.

Table 2. Analysis of issues associated with hospital mortality.

\begin{tabular}{lccc}
\hline & Death & Survival & p-value \\
\hline Sample size & 31 & 89 & \\
Gender (female) & $19(61 \%)$ & $47(53 \%)$ & 0.41 \\
Age (years) & $76 \pm 11$ & $75 \pm 8.3$ & 0.81 \\
Disease duration (years) & $0.39 \pm 0.80$ & $1.33 \pm 2.47$ & 0.04 \\
Diabetes & $12(39 \%)$ & $26(29 \%)$ & 0.33 \\
Hypertension & $27(87 \%)$ & $79(89 \%)$ & 0.83 \\
Dyslipidemia & $7(30 \%)$ & $24(36 \%)$ & 0.61 \\
Status epilepticus & $7(23 \%)$ & $2(2.2 \%)$ & $<0.001$ \\
Acute symptomatic seizure & $2(6.5 \%)$ & $7(7.9 \%)$ & 0.80 \\
Epilepsy etiology & & & \\
Ischemic stroke & $11(36 \%)$ & $33(37 \%)$ & 0.87 \\
Hemorrhagic stroke & $2(6.5 \%)$ & $12(14 \%)$ & 0.29 \\
Neoplasia & $5(16 \%)$ & $11(12 \%)$ & 0.60 \\
Alzheimer's disease & $1(3.2 \%)$ & $7(7.9 \%)$ & 0.37 \\
Other dementias & $2(6.5 \%)$ & $4(4.5 \%)$ & 0.67 \\
Metabolic disorders & $5(16 \%)$ & $2(2.2 \%)$ & 0.005 \\
\hline
\end{tabular}

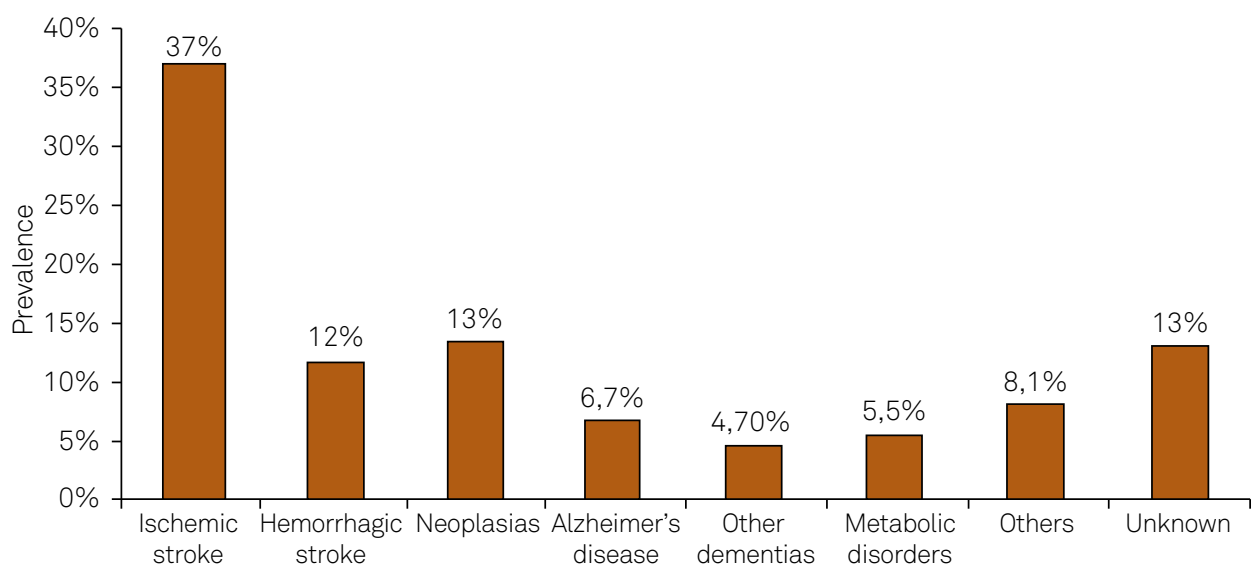

Figure 1. Etiological prevalence of epilepsy among the 120 patients. 


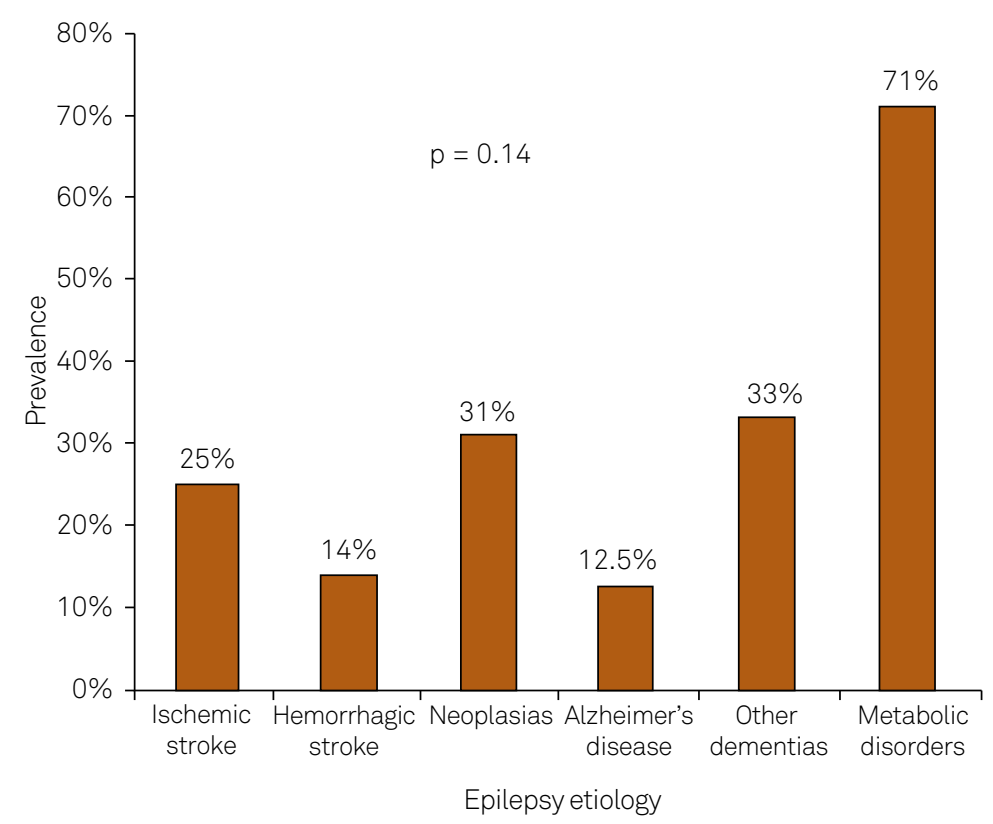

Figure 2. Mortality percentage and etiology of epileptic seizures among the 120 patients.

Table 3. Logistic regression analysis to identify independent predictors of hospital mortality.

\begin{tabular}{lccc}
\hline & Odds ratio & $95 \% \mathrm{Cl}$ & $\mathrm{p}$-value \\
\hline Status Epilepticus & 12.8 & $2.3-72.2$ & 0.004 \\
Metabolic disorder & 3.7 & $0.57-24.5$ & 0.17 \\
Disease duration & 0.68 & $0.45-1.03$ & 0.07 \\
\hline
\end{tabular}

Cl: confidence interval.

\section{DISCUSSION}

We identified 120 (15\%) of elderly inpatients with newonset epilepsy and epileptic seizures. Of the total, 18 (15\%) patients had seizures as the main reason for hospitalization and the remaining were hospitalized due to several neurological disorders. We found no statistical significant difference of the distribution of epilepsy and epileptic seizures by gender, similar to previous published studies ${ }^{20,21}$.

Generalized seizures (37.2\%) were more common than focal seizures, in this population, and we found a high proportion of seizures which were not classified (38\%), unlike to what has been reported in most studies on epilepsy and epileptic seizures in aging people. Unfortunately there are few studies addressed to elderly hospitalized population in which comorbidities such as metabolic disturbances, anoxic encephalopathy, and seizures induced by drugs contribute mostly to the occurrence of seizures generalized type. This high proportion of generalized type seizures in our sample may probable represent indeed focal seizures which the onset of the event was no witnessed or described in medical records. We had 31(28\%) EEG performed during hospitalization and merely $32 \%$ of them had epileptiform activity.

The most common etiology associated with epilepsy and epileptic seizures was stroke (49\%). Of the 120 patients, $88 \%$ had systemic arterial hypertension as comorbidity, the most significant risk factor for stroke ${ }^{10}$. When analyzing systemic arterial hypertension, diabetes mellitus and dyslipidemia, we found that none of these comorbidities was an independent risk factor for seizures.

In our study we identified only one patient who developed acute seizures in the course of acute ischemic stroke. Epilepsy and epileptic seizures are more common after subarachnoid than intracerebral hemorrhage and risk factors for seizures include secondary bleeding, presence of large amount of blood in the subarachnoid space including basal cisterns, or ischemic complications ${ }^{22}$. Hemorrhagic stroke, in our sample, accounted for $12 \%$ of the cases, and, among these, there were eight cases of subarachnoid hemorrhage. The relative scarcity of cases of hemorrhagic stroke in this sample is explained by the fact that most of these patients are attended by the neurosurgery service of the hospital.

In our sample, $58(48 \%)$ of patients were submitted to neuroimaging exams thus, we could not obtain enough data to correlate location and type of etiologic stroke with the epilepsy or epileptic seizure.

Intracranial neoplasias were the second most frequent cause associated with epilepsy and epileptic seizures (13\%). Brain metastases were the most prevalent malignancies, occurring in 11 patients while primary tumors of CNS occurred in the remaining cases. Older people with brain tumors are less likely to present seizures than younger patients, but age is a risk factor for increased mortality in those who develop seizures ${ }^{12}$.

Dementias were the third most common etiology associated with epilepsy and epileptic seizures (11.4\%). In this group, probable Alzheimer's disease was responsible for $6.7 \%$ of cases while for the remaining, the causes assigned 
of cognitive impairment were mixed dementia, vascular and Lewy Body. In Alzheimer's disease, the frequency of epilepsy is $10-22^{23}$.

Metabolic disorders occurred in $5.5 \%$ of the patients and the main causes were uremia, liver failure, hypoglycemia, hyponatremia and hypoxia. Acute symptomatic seizures in the elderly, like occur in young individuals may be secondary to acute complications such as fever, liver or renal diseases and electrolyte disturbances. Hyperglicemia or hypoglycemia related to insulin can cause seizures in elderly diabetics ${ }^{8,14}$.

Five patients had seizures associated with the use of drugs with potential proconvulsant effects such as antibiotics like quinolones (3 patients used ciprofloxacin), and beta-lactams (2 patients used carbapenems). This group of patients had severe diseases associated with other several conditions known to be related with increased risk of seizures, such as meningitis, septicemia and metabolic encephalopathy. Elders, especially those hospitalized and more seriously ill are a vulnerable population and are exposed to high risk of experiencing seizures precipitated by drugs. Drug-induced seizures are potentially related to the use of more than one drug, high doses, parenteral administration and comorbidity. Convulsive and non-convulsive status epilepticus (SE) have been related to prescription drugs, and it is estimated that $15 \%$ of patients with seizures secondary to drug use can develop SE ${ }^{15}$.

We had one patient who had seizures due to antiepileptic drugs (AED) withdrawal.

SE occurred in $7.5 \%$ (9) of patients and was most related to toxic-metabolic cause (5 patients). Higher mortality rate, was found in those patients who presented SE, $78 \%$ (7 patients). The high mortality rate ascertained in our study is similar to that described by most authors and also shows a strong dependence on etiological factors and age $^{24,25}$. The data from some studies showed that SE was associated with a mortality rate ranging from $38 \%$ to $50 \%$ in patients older than 80 years of age and it may reach $100 \%$ in patients with anoxia ${ }^{26,27}$. The most common etiologies associated with SE in elders are: stroke, hypoxia, metabolic disturbances, alcohol-related, tumor, sepsis, anoxia, trauma and low antiepileptic drug concentration ${ }^{16}$. Seizures descriptions were lack in the clinical records, so we could not classify the type of SE. However, as the clinical manifestations of non convulsive SE vary from mild impairment of consciousness to deep coma, it's possible that this condition has been underecognized.

The mortality in this sample was associated with SE, metabolic disturbance and disease duration, also. The patients who died with shorter duration of disease, were the most severely ill and, so, they had shorter hospital stay, culminating in death. After adjustment of the variables SE, metabolic cause and disease duration, the SE was an independent predictor of death, probably because was associated with toxic-metabolic cause. However, metabolic etiology, after adjustment remained not related to death. It's important to highlight that the broad value of confidence interval obtained, was due to the small number of patients with SE in this sample, and this can make doubtful the result found.

The current study shows that only a small proportion of patients $(12.5 \%)$ had not identified the etiology of their epileptic seizures, in agreement with another study of elderly hospitalized patients ${ }^{28}$. The high frequency of unknown causes in population studies contrasts with the large number of symptomatic etiologies in hospitalized patients. Even with the advent of neuroimaging, nearly $25 \%$ to $40 \%$ of cases of new-onset epilepsy in the elderly have not identified their etiology ${ }^{3,29,30}$. The opportunity for greater care in the investigation of the hospitalized patients resulted in a higher rate of etiological definition compared to previously reported data.

Although the relatively large and homogenous sample of patients, this study has several limitations to highlight. The most important of these is the retrospective nature of the study design. In the analysis of clinical records, we could not obtain all the information needed to answer important questions such as, seizures' type description, the lag between the beginning of stroke (in stroke etiology) and the onset of seizures. The attempts to obtain those answers, by contact with family or caregiver, were not always succeeded, especially when the patient at issue had died. Because of the stigma of epilepsy, that can be profound, the diagnosis commonly strikes patients and their families. Another limitation is related to the scarcity of complementary tests like EEG and neuroimaging exams during hospitalization. There were no reported cases that had undergone EEG monitoring. Nevertheless, only a small proportion of patients had no etiological diagnosis elucidated. However, it seems likely that we may have fail to record less serious cases that had received lower level of attention.

It is important to improve understanding of possible risk factors and the many conditions associated with new-onset epilepsy in the elderly, especially those related to the hospital environment, considering that they may predispose the brain to seizures. Age-related changes in renal and hepatic functions, comorbidities and comedications may contribute to facilitating the occurrence of SE and the AED treatment should be established taking these issues into account. Despite the higher morbidity and mortality related to epilepsy, with proper handling most patients become seizure free. Although SE in aged population is increasingly common, assistance to most of these patients is generally suboptimal. Future clinical studies are needed and may contribute to identify the mortality risk factors in these patients, and thereby develop effective strategies to avoid the excess mortality.

In conclusion, our findings suggest that, in this population, status epilepticus, metabolic disorders and disease duration were associated with hospital death. Status epilepticus was an independent risk factor for mortality. 
1. Huber DP, Griener R, Trinka E. Antiepileptic drug use in Austrian nursing home residents. Seizure. 2013;22(1):24-7. http://dx.doi.org/10.1016/j.seizure.2012.09.012

2. Annegers JF, Hauser WA, Lee JR, Rocca WA. Incidence of acute symptomatic seizures in Rochester, Minnesota, 1935-1984. Epilepsia. 1995;36(4):327-33. http://dx.doi.org/10.1111/j.1528-1157.1995.tb01005.x

3. Hauser WA, Annegers JF, Kurland LT. Incidence of epilepsy and unprovoked seizures in Rochester, Minnesota: 1935-1984. Epilepsia. 1993;34(3):453-68. http://dx.doi.org/10.1111/j.1528-1157.1993.tb02586.x

4. Berg AT. Epilepsy is common in the elderly, but where does it go? Neurology. 2012;78(7):444-5. http://dx.doi.org/10.1212/WNL.0b013e318246d70b

5. Nevalainen O, Ansakorpi H, Simola M, Raitanen J, Isojärvi J, Artama M et al. Epilepsy-related clinical characteristics and mortality: a systematic review and meta-analysis. Neurology. 2014;83(21):1968-77. http://dx.doi.org/10.1212/WNL.0000000000001005

6. Forsgren L, Hauser WA, Olafsson E, Sander JW, Sillanpaa M, Tomson T. Mortality of epilepsy in developed countries: a review. Epilepsia. 2005;46(suppl s11):18-27. http://dx.doi.org/10.1111/j.1528-1167.2005.00403.x

7. DeLorenzo RJ, Kirmani B, Deshpande LS, Jakkampudi V, Towne $A R$, Waterhouse $E$ et al. Comparisons of the mortality and clinical presentations of status epilepticus in private practice community and university hospital settings in Richmond, Virginia. Seizure. 2009;18(6):405-11. http://dx.doi.org/10.1016/j.seizure.2009.02.005

8. Rowan AJ. Reflections on the treatment of seizures in the elderly population. Neurology. 1998;51 (5 Suppl 4):S28-33. http://dx.doi.org/10.1212/WNL.51.5_Suppl_4.S28

9. Brodie MJ, Elder AT, Kwan P. Epilepsy in later life. Lancet Neurol. 2009;8(11):1019-30. http://dx.doi.org/10.1016/S1474-4422(09)70240-6

10. Beghi E, D’Alessandro R, Beretta S, Consoli D, Crespi V, Delai Let al. Incidence and predictors of acute symptomatic seizures after stroke. Neurology. 2011;77(20):1785-93. http://dx.doi.org/10.1212/WNL.0b013e3182364878

11. Brodie MJ, Kwan P. Epilepsy in elderly people. BMJ. 2005;331(7528):1317-22. http://dx.doi.org/10.1136/bmj.331.7528.1317

12. Stephen LJ, Brodie MJ. Epilepsy in elderly people. Lancet. 2000;355(9213):1441-6. http://dx.doi.org/10.1016/S0140-6736(00)02149-8

13. Shorvon SD, Tallis RC, Wallace HK. Antiepileptic drugs: coprescription of proconvulsant drugs and oral contraceptives: a national study of antiepileptic drug prescribing practice.J Neurol Neurosurg Psychiatry. 2002;72(1):114-5. http://dx.doi.org/10.1136/jnnp.72.1.114

14. Waterhouse E, Towne A. Seizures in the elderly: nuances in presentation and treatment. Cleve Clin J Med. 2005;72(Suppl 3):S26-37. http://dx.doi.org/10.3949/ccjm.72.Suppl_3.S26
15. Misra UK, Kalita J, Chandra S, Nair PP. Association of antibiotics with status epilepticus. Neurol Sci. 2013;34(3):327-31. http://dx.doi.org/10.1007/s10072-012-1001-5

16. Towne AR. Epidemiology and outcomes of status epilepticus in the elderly. Int Rev Neurobiol. 2007;81:111-27. http://dx.doi.org/10.1016/S0074-7742(06)81007-X

17. Carpio A, Hauser WA. Epilepsy in the developing world. Curr Neurol Neurosci Rep. 2009;9(4):319-26. http://dx.doi.org/10.1007/s11910-009-0048-z

18. Blume WT, Lüders HO, Mizrahi E, Tassinari C, Boas WE, Engel Jr J. Glossary of descriptive terminology for ictal semiology: report of the ILAE task force on classification and terminology. Epilepsia. 2001;42(9):1212-8. http://dx.doi.org/10.1046/j.1528-1157.2001.22001.x

19. Beghi E, Carpio A, Forsgren L, Hesdorffer DC, Malmgren $\mathrm{K}$, Sander JW et al. Recommendation for a definition of acute symptomatic seizure. Epilepsia. 2010;51(4):671-5. http://dx.doi.org/10.1111/j.1528-1167.2009.02285.x

20. Paradowski B, Zagrajek MM. Epilepsy in middle-aged and elderly people: a three-year observation. Epileptic Disord. 2005;7(2):91-5.

21. Faught E, Richman J, Martin R, Funkhouser E., Foushee R, Kratt $P$ et al. Incidence and prevalence of epilepsy among older U.S. Medicare beneficiaries. Neurology. 2012;78(7):448-53. http://dx.doi.org/10.1212/WNL.0b013e3182477edc

22. Krämer G. Epilepsy in the elderly: some clinical and pharmacotherapeutic aspects. Epilepsia. 2001;42(Suppl s3):55-9. http://dx.doi.org/10.1046/j.1528-1157.2001.042suppl.3055.x

23. Mendez M, Lim G. Seizures in elderly patients with dementia: epidemiology and management. Drugs Aging. 2003;20(11):791-803. http://dx.doi.org/10.2165/00002512-200320110-00001

24. Assis TM, Costa G, Bacellar A, Orsini M, Nascimento OJ. Status epilepticus in the elderly: epidemiology, clinical aspects and treatment. Neurol Int. 2012;4(3):e17. http://dx.doi.org/10.4081/ni.2012.e17

25. Bhalla D, Tchalla AE, Mignard C, Marin B, Mignard D, Jallon P et al. First-ever population-based study on status epilepticus in French Island of La Reunion (France) - incidence and fatality. Seizure. 2014;23(9):769-73. http://dx.doi.org/10.1016/j.seizure.2014.06.009

26. Verellen RM, Cavazos JE. Pathophysiological considerations of seizures, epilepsy, and status epilepticus in the elderly. Aging Dis. 2011;2(4):278-85.

27. Towne AR, Pellock JM, Ko D, DeLorenzo RJ. Determinants of mortality in status epilepticus. Epilepsia. 1994;35(1):27-34. http://dx.doi.org/10.1111/j.1528-1157.1994.tb02908.x

28. Ettinger AB, Shinnar S. NewDonset seizures in an elderly hospitalized population. Neurology. 1993;43(3 Pt 1):489-92. http://dx.doi.org/10.1212/WNL.43.3_Part_1.489

29. Cloyd J, Hauser W, Towne A, Ramsay R, Mattson R, Gilliam Fet al. Epidemiological and medical aspects of epilepsy in the elderly. Epilepsy Res. 2006;68 Suppl 1:S39-48. http://dx.doi.org/10.1016/j.eplepsyres.2005.07.016

30. Leppik IE. Introduction to the International Geriatric Epilepsy Symposium (IGES). Epilepsy Res. 2006;68 Suppl 1:S1-4. http://dx.doi.org/10.1016/j.eplepsyres.2005.07.010 